\title{
Fatty acid composition and antioxidant activity of oils from two cultivars of Cantaloupe extracted by supercritical fluid extraction
}

\author{
By Maznah Ismail, ${ }^{\text {a }}{ }^{*}$ Abdalbasit Mariod, ${ }^{\text {ac }}$ Gururaj Bagalkotkar ${ }^{\mathrm{a}}$ and Hoe Sy Ling ${ }^{\mathrm{b}}$
}

\author{
${ }^{a}$ Laboratory of Molecular BioMedicine, Institute of Bioscience, Universitiy Putra \\ Malaysia, 43400 UPM, Serdang, Selangor, Malaysia \\ ${ }^{\mathrm{b}}$ Department of Nutrition and Dietetics, Faculty of Medicine and Health Sciences, University Putra \\ Malaysia, 43400 UPM, Serdang, Selangor, Malaysia. \\ ${ }^{c}$ Department of Food Science \& Technology, Sudan University of Science \&Technology, P. O. Box 71, \\ Khartoum North, Sudan \\ ( ${ }^{*}$ Corresponding author: maznahis@ putra.upm.edu.my \& maznah@ medic.upm.edu.my)
}

\section{RESUMEN}

\begin{abstract}
Actividad antioxidante y composición de ácidos grasos de aceites de semilla de melón de dos variedades extraídos mediante extracción con fluido supercrítico

El efecto del fraccionamiento mediante extracción con fluido supercrítico de tres fracciones (fracción $1^{\mathrm{a}}, 2^{\mathrm{a}}$ y $3^{\mathrm{a}}$ ) sobre la composición de ácidos grasos y actividad antioxidante de aceites de dos variedades de melón fué investigado. Aceites de melón de los cultivares Rock (RMO) y Golden Langkawi GLO) fueron extraídos usando SFE y los principales ácidos grasos en cada cultivar fueron ácido linoleico, oleico, palmítico y esteárico. Los ácidos grasos saturados (SFA) disminuyeron desde 15.78 a $14.14 \%$ en la $1^{\text {a }}$ fracción de $\mathrm{RMO}$ y los ácidos grasos monoinsaturados (MUFA) disminuyeron desde 18.30 a $16.56 \%$ en la $2^{\mathrm{a}}$ fracción de $\mathrm{RMO}$, mientras que los ácidos grasos poliinsaturados (PUFA) aumentaron de 65.9 a $69.30 \%$ en la $3^{\mathrm{a}}$ fracción de RMO. Por otra parte, SFA disminuyo de 16.35 a $13.91 \%$ en la primera fracción de GLO y MUFA disminuyo de 17.50 a $15.57 \%$ en la $2^{\mathrm{a}}$ fracción de GLO, mientras que PUFA aumento de 66.15 a $70.52 \%$ en la $3^{\mathrm{a}}$ fracción de GLO. Las diferentes fracciones de los dos aceites mostraron una alta actividad antioxidante al reducir la oxidación del $\beta$-caroteno en el ensayo de decoloración de beta-carotene $(\mathrm{BCB})$ y en la eliminación del radical 1,1-difenil-2-picrilhidrazilo (DPPH).
\end{abstract}

PALABRAS CLAVE: Ácido graso - Actividad antioxidante - 1,1-difenil-2-picrilhidrazylo - Ensayo de decoloración de beta-caroteno - Extracción con fluido supercrítico - Melón

\section{SUMMARY}

Fatty acid composition and antioxidant activity of oils from two cultivars of Cantaloupe extracted by supercritical fluid extraction

The effect of supercritical fluid extraction (SFE) fractionation of three oil fractions $\left(1^{\text {st }}, 2^{\text {nd }}, 3^{\text {rd }}\right.$ fraction $)$ on the fatty acid composition and antioxidant activity of oils from two cultivars of cantaloupe were investigated. Rock melon oil (RMO) and Golden Langkawi oil (GLO) were extracted using SFE and the major fatty acids for both cultivars were linoleic, oleic, palmitic, and stearic acid. The SFA decreased from 15.78 to $14.14 \%$ in RMO $1^{\text {st }}$ fraction, and MUFA decreased from 18.30 to $16.56 \%$ in RMO $2^{\text {nd }}$ fraction, while PUFA increased from 65.9 to $69.30 \%$ in $\mathrm{RMO} 3^{\text {rd }}$ fraction. On the other hand SFA decreased from 16.35 to $13.91 \%$ in GLO $1^{\text {st }}$ fraction, and MUFA decreased from 17.50 to $15.57 \%$ in GLO $2^{\text {nd }}$ fraction, while PUFA increased from 66.15 to $70.52 \%$ in GLO $3^{\text {rd }}$ fraction. The different fractions of the two oils showed high antioxidant activity in reducing the oxidation of $\beta$-carotene in beta-carotene bleaching assay $(\mathrm{BCB})$ and the quenching of 1,1-diphenyl-2-picrylhydrazyl (DPPH).

KEY-WORDS: Antioxidant activity - Beta-carotene bleaching assay - Cantaloupe - 1,1-diphenyl-2-picrylhydrazyl - Fatty acid - Supercritical fluid extraction.

\section{INTRODUCTION}

The cantaloupe, from the family cucurbitaceae, refers to two different varieties, Cucumis melo cantalupensis known locally as Golden langkawi and Cucumis melo reticulates which is known locally as rock melon (Integrated Taxonomic System, 2007). Several authors (Al-Khalifa, 1996; Kamel et al., 1985; Badlfu, 1991) have reported studies about some melon seeds and compared the physicochemical characteristics of their oils with those from conventional sources. Melon (Cucumis melo) seeds, besides possessing medicinal qualities (Bellakhdar et al. 1991), are also a rich source of protein $(53.90 \%)$ and oil $(37.67 \%)$ (Mariod et al. 2008; Rashwan et al. 1993). The proximate composition of the seeds or seed kernels of the Cucumis melo from different origin and varieties has been reported (Teotia and Ramakrishna 1984; Kaur et al. 1988; Tekin and Velioglu, 1993). as well as the fatty acid composition of the seed oil from Egypt (El-Magoli et al. 1979), India (Hemavatahy 1992), Sudan (Mariod et al. 2008) and Vietnam (Imbs and Pham, 1995). Maria et al. (2001) showed that the oil of Cucumis melo contains myristic acid $(0.3 \%)$, stearic acid $(6.1 \%)$, palmitic acid $(8.5 \%)$, oleic acid $(31 \%)$ and linoleic acid $(51 \%)$. They showed that the Cucumis melo seed oil which was obtained by Soxhlet extraction contained $15.3 \%$ saturated fatty acid and $82.8 \%$ unsaturated fatty acid, which 
further consisted of $26.2 \%$ as monounsaturated fatty acid and $56.6 \%$ as polyunsaturated fatty acid. Pumpkin seed extracts of different polarity and phenolic content are able both to quench DPPH free radicals and to inhibit lipid peroxidation catalyzed by lipoxygenase (Xanthopoulou et al., (2009). Budrat and Shotipruk (2009) presented a study which demonstrated that bitter melon is an important source of phenolic compounds which possess strong antioxidant activity.

Oils that are extracted by using environmental hazardous organic solvents such as $n$-hexane or petroleum ether might contain residual solvent due to the incomplete solvent removal. Supercritical fluid extraction (SFE) with supercritical carbon dioxide $\left(\mathrm{SC}-\mathrm{CO}_{2}\right)$ has received considerable attention which can be an alternative method for the extraction of oils from foods and natural products (Gomes et al. 2007; Lu et al. 2007). It is because carbon dioxide is both non-toxic and nonexplosive and its use can reduce the consumption of organic solvents; which is especially useful for the production of natural products used in foods and pharmaceuticals (Leo et al. 2005). The oils obtained by $\mathrm{SC}-\mathrm{CO}_{2}$ extraction are of outstanding quality and the yields are comparable with those by organic solvent extraction methods (Friedrich and List, 1982; Gómez et al. 1996). In fact, SFE extracts are generally recognized as safe (GRAS) to be used in food products (Gerard \& May, 2002). Therefore, SFE may serve as a very promising technology in food and pharmaceutical processing (King, 2000).

Several methods have been recommended for the evaluation of antioxidant properties of plant materials and some methods in current use were compared (Gordon, 1990; Ou et al., 2002). 2,2'-diphenyl-1picrylhydrazyl radical (DPPH ${ }^{*}$ ) assay is a well known method for the evaluation of free radical-scavenging activity. The method is polarity-independent, very rapid, simple and reproducible (Koleva et al. 2002). Fatty acid decomposition is one of the main causes of food spoilage and hence inhibition of fatty acid oxidation is an important issue in the food industry. Food preservatives or antioxidants are mainly used as inhibitors of the oxidation of fatty acids. Therefore, the inhibition of linoleic acid oxidation can be measured in the presence of $\beta$-carotene that is used as a marker (Dapkevicius et al. 1998). Linoleic acid oxidation produces conjugated dienes and other volatile products that attack $\beta$-carotene and bleach its characteristic color (pale yellow in aqueous emulsion). In general, both free radical-scavenging and inhibition of linoleic acid oxidation are desired in the food industry.

Although the $C$. cantalupensis and $C$. reticulates melons are recently produced and consumed in Malaysia, there are however no studies on fatty acid composition, antioxidant properties and the health benefits of oils from these two species. Therefore, the objective of the work was the characterization of three oil fractions from successive extractions using SFE in terms of fatty acid composition and antioxidant activity by means of 2,2-diphenyl-1picrylhydrazyl (DPPH) radical-scavenging assay and $\beta$-carotene bleaching test.

\section{MATERIALS AND METHODS}

\subsection{Materials}

Golden Langkawi and rock melon were obtained from the MAHA (Malaysian Agriculture, Horticulture and Agrotourism) fair organized by Malaysia Agricultural Research and Development Institute (MARDI), Serdang, Selangor, Malaysia.

The chemicals used were of analytical reagent grade that include 1,1-diphenyl-2-picrylhydrazyl (DPPH - 90\% purity), (+)- $\alpha$-tocopherol, -carotene (Type I synthetic, 95\%) and linoleic acid (99\%), were obtained from Sigma-Aldrich Co., St. Louis, MO, USA), toluene (Merck, Darmstadt, Germany), $n$-hexane and chloroform (Fisher Scientific, Loughborough, Leicestershire, UK), carbon dioxide (99.8\%, Malaysian Oxygen Berhad, Petaling Jaya, Selangor, Malaysia), Tween 20 and absolute ethanol (Fisher Scientific, Loughborough, Leicestershire, UK).

\subsection{Methods}

\section{Preparation of dried cantaloupe seeds}

Cantaloupe seeds collected from the fruits were cleaned and dried to constant weight at $50^{\circ} \mathrm{C}$ in a drying oven (FD 115, Fisher Scientific, Loughborough, Leicestershire, UK). The final moisture content of the seeds was $4.43 \pm 0.07 \%$. The dried seeds were ground using a blender (Waring, Torrington, CT, USA) and kept at $4^{\circ} \mathrm{C}$ prior to oil extraction.

\section{Supercritical fluid extraction (SFE) with carbon dioxide}

Cantaloupe seeds were extracted using a Supercritical Carbon Dioxide Extractor (Thar 1000 F, Thar Technologies, Inc., Pittsburgh, PA, USA) at a pressure (bars)/temperature (C) of 600/40 with three successive extractions for $1 \mathrm{~h}$ each $\left(1^{\mathrm{st}}, 2^{\text {nd }}\right.$ or $3^{\text {rd }}$ fraction) according to the method described by Bruhl and Matthaus (1999). Briefly, one hundred grams of cantaloupe seed powder was placed into a $1 \mathrm{~L}$ extraction vessel. The extractor was sealed, oven temperature was set at $40^{\circ} \mathrm{C}$ and pressurized to 600 bars. Pressure within the extraction vessel was built up with a constant carbon dioxide flow rate of $25 \mathrm{~g} / \mathrm{min}$ and regulated by an automated back pressure regulator. The collection flask was kept at ambient pressure and temperature of $60^{\circ} \mathrm{C}$. The SFE extraction was initiated after the desirable temperature and pressure were achieved. The extracted oil from the extraction vessel was collected every hour for $3 \mathrm{~h}$ in order to obtain different fractions and the yield of the oil 
was measured. After the extraction was completed, the extraction vessel was depressurized and the oil was collected. The cooled flask containing the oil was weighed and the oil content was calculated.

\section{Cantaloupe seed oil extracted by Soxhlet method}

The cantaloupe seed oil was extracted by Soxhlet following the AOAC method (1990). Briefly, about $10 \mathrm{~g}$ of dried sample were placed into a dried extraction thimble, with porosity permitting a rapid flow of petroleum ether. The sample in the thimble was covered with wool. The pre-dried boiling flask was weighed. Petroleum ether was placed in the boiling flask. The sample was extracted in a Soxhlet extractor for $6 \mathrm{~h}$ at a rate of 2 to 3 drops per second by the heated solvent in the boiling flask. The boiling flask with extracted fat was dried in an air oven at $100^{\circ} \mathrm{C}$ for $30 \mathrm{~min}$, cooled in a desiccator, and weighed.

\section{Determination of oil content and fatty acid composition of cantaloupe seed oil by gas chromatography.}

The oil content was determined using the AOCS method Am 2-93 (1993), while fatty acid composition in cantaloupe seed oil was determined using gas chromatography according to the method described by Baye and Becker (2004). Seed oil (100 mg) was weighed into $20 \mathrm{ml}$ test tubes and dissolved in $10 \mathrm{ml}$ hexane. Then, $100 \mu \mathrm{l}$ of $2 \mathrm{~N}$ potassium hydroxide in methanol (11.2 $\mathrm{g}$ in 100 $\mathrm{ml}$ ) was added into the test tube, vortexed for 30 seconds and centrifuged (Hettich Rotofix, Ramsey, $\mathrm{MN}, \mathrm{USA})$. The clear supernatant $(2 \mathrm{ml})$ was transferred to an auto sampler vial and injected into gas chromatography (Agilent GC 68, Santa Clara, CA, USA) for analysis. The column used was DB-23, diameter $250 \mu \mathrm{m}$, length $60 \mathrm{~m}$, film thickness $0.25 \mu \mathrm{m}$, and the void time was 3.017 min. The peak areas were computed by integration software and percentages of fatty acid methyl esters (FAME) were obtained as weight percent by direct internal normalization with the Agilent Technologies ChemStation software. All analyses were performed in triplicate.

\section{Antioxidant activity (AOA) measurements}

1, 1-Diphenyl-2-picrylhydrazyl (DPPH) radical scavenging activity test. The antioxidant activity of cantaloupe oils was measured according to the method described by Ramadan, et al. (2006). BHT was used as the standard lipophilic antioxidant in this test. In brief, $0.1 \mathrm{~mL}$ of toluenic sample solution at different concentrations was added with $0.39 \mathrm{~mL}$ fresh toluenic DPPH solution $(0.1 \mathrm{mM})$. Then, the mixture was shaken vigorously and left in the dark for $60 \mathrm{~min}$. Finally, the absorbance of the mixture was measured against pure toluene (blank) at $515 \mathrm{~nm}$ by using a UV-Visible spectrophotometer
(Pharmaspec UV-1700, Shimadzu, Kyoto, Japan). The absorbance of the DPPH radical without antioxidant, i.e. the control was measured. The data is commonly reported as $I_{50}$, which is the concentration of antioxidant required for $50 \%$ scavenging of DPPH radicals in the specified time period. All determinations were made in triplicate

The $\beta$-carotene-linoleic acid assay. The antioxidant activity (AOA) of the different fractions was evaluated using the $\beta$-carotene-linoleic acid assay following the method of Amarowicz et al. (2003). In brief, a solution of $\beta$-carotene was prepared by dissolving $2 \mathrm{mg}$ of $\beta$-carotene in $10 \mathrm{ml}$ of chloroform. Two milliliters of this solution were pipetted into a $100 \mathrm{ml}$ round-bottom flask. After chloroform was removed under vacuum, using a rotary evaporator at $40{ }^{\circ} \mathrm{C}, 40 \mathrm{mg}$ of purified linoleic acid, $400 \mathrm{mg}$ of Tween 40 as an emulsifier, and $100 \mathrm{ml}$ of aerated distilled water were added to the flask with vigorous shaking. Aliquots (4.8 $\mathrm{ml}$ ) of this emulsion were transferred into a series of tubes containing $200 \mu \mathrm{l}$ of the extract $(200 \mathrm{ppm}$ in methanol). The total volume of the systems was adjusted to $5 \mathrm{ml}$ with methanol. As soon as the emulsion was added to each tube, the zero time absorbance was measured at $470 \mathrm{~nm}$ with a Shimadzu spectrophotometer (Shimadzu Co., Ltd., Kyoto, Japan). Sub-sequent absorbance readings were recorded by keeping the samples in a water bath at $50^{\circ} \mathrm{C}$. Blank samples, devoid of $\beta$-carotene, were prepared for background subtraction.

\subsection{Statistical analyses}

Statistical analyses were conducted using SPSS (Statistical Program for Social Sciences, SPSS Corporation, Chicago, IL) version 12.0 for Windows. Analysis of variance (ANOVA) and Pearson's correlation coefficients were performed to compare the data. All determinations were made at least in triplicate and all were averaged. The confidence limits used in this study were based on 95\% $(P<0$.

\section{RESULTS AND DISCUSSION}

\subsection{The total oil content of $C$. cantalupensis and $C$. reticulates seeds}

In a previous study (Chan and Ismail 2009), our group showed that using the extraction pressure 600 bars and temperature of $40^{\circ} \mathrm{C}$ gave a high yield of oil extraction for Hibiscus cannabinus using SFE. Depending on that result we used 600/40 extraction parameters for the extraction of the cantaloupe oil. Table 1 shows the yield of the two varieties of cantaloupe seed oil through 600/40 SFE extraction parameters in comparison with the conventional Soxhlet method. In general, the total oil content obtained from SFE for $C$. reticulates was $30.4 \%$ and for $C$. cantalupensis was $22.7 \%$. On the other hand, the total oil content obtained from Soxhlet extraction 
was found to be significantly higher $(P<0.05)$. C. reticulates was $33.5 \%$ and $C$. cantalupensis was $29.8 \%$. These results are in agreement with those obtained by Teotia \& Ramakrishna (1984) and Maria et al. (2001), who reported $33.0 \%$ and $32.3 \%$, respectively, for melon seed using Soxhlet extraction. It can be observed that the total oil content obtained by Soxhlet extraction was 3.08\% higher for $C$. reticulates and $7.14 \%$ higher for $C$. cantalupensis than the amount obtained by SFE, but $\mathrm{CO}_{2}$ reverts to a gas at room temperature and pressure and has minor toxicity. In addition to that, SFE extraction is safer because there is no leftover contaminant in the extract because the carbon dioxide is allowed to escape in the form of a gas. It was therefore easy to conclude that SFE with $\mathrm{CO}_{2}$ would offer clear advantages over organic solvents for oil analysis.

The total oil content of $C$. cantalupensis obtained from SFE $1^{\text {st }}$ fraction was $15.2 \%$, $2^{\text {nd }}$ hour was $5.7 \%$ and the $3^{\text {rd }}$ fraction was $1.8 \%$ of the dried seeds. Whereas the amount of oil obtained from $C$. reticulates $1^{\text {st }}, 2^{\text {nd }}$ and $3^{\text {rd }}$ fraction was $22.0 \%, 6.0 \%$, and $2.4 \%$, respectively (Table 1 ). From the SFE fractionation of two cantaloupe species, results showed that the amount of oil obtained for both species decreased with time because most of the oil $(65 \%$ and $75 \%)$ was already extracted from both seeds in the first hour of SFE extraction. So the oil content from the $2^{\text {nd }}$ and $3^{\text {rd }}$ fractions was less than the first hour of SFE fraction.

\subsection{Fatty acid composition}

The fatty acid profiles of seed oil from the C. reticulates (RMO) were analyzed by $\mathrm{GC}$, as summarized in Table 2. The major fatty acids present in the SFE fractions from $C$. reticulates was linoleic acid (65\%), followed by oleic acid (16.3\%), palmitic acid $(8.1 \%)$, stearic acid $(5.5 \%)$, arachidic acid $(2.9 \%)$, eicosanoic acid $(1.1 \%)$, linolelaidic acid $(0.25 \%), \alpha$-linolenic acid $(0.13 \%)$, and $\gamma$-linolenic acid $(0.06 \%)$. Whereas no significant changes in the amounts of oleic, stearic and palmitic acids from $1^{\text {st }}$ fraction, $2^{\text {nd }}$ fraction and $3^{\text {rd }}$ fraction were found, this is not in accordance with the findings of Yu et al. (1994), who studied the solubilities of fatty acids, fatty acid ester, triglycerides, and fats and oils in supercritical carbon dioxide, where they reported that linoleic acid decreased while oleic, stearic and palmitic acid increased over extraction time.

The fatty acid composition of RMO obtained from SFE $1^{\text {st }}$ fraction was $15.78 \%$ of saturated fatty acid (SFA), $18.30 \%$ of monounsaturated fatty

Table 1

Percent oil content on a dry basis in seeds of two cantaloupe species obtained with soxhlet and SFE*

\begin{tabular}{lcc}
\hline Sample & C. reticulates & C. cantalupensis \\
\hline Soxhlet method & $33.5 \pm 0.4$ & $29.8 \pm 0.5$ \\
SFE $1^{\text {st }}$ fraction & $22.0 \pm 0.2$ & $15.2 \pm 0.3$ \\
SFE $2^{\text {nd }}$ fraction & $6.0 \pm 0.3$ & $5.7 \pm 0.2$ \\
SFE $3^{\text {rd }}$ fraction & $2.4 \pm 0.3$ & $1.8 \pm 0.1$ \\
Total content oil by SFE & 30.4 & 22.7 \\
\hline
\end{tabular}

*All supercritical fluid extraction (SFE) fractions were performed at 600 bars and

$40^{\circ} \mathrm{C}$. All determinations were carried out in triplicate and mean value \pm SD reported.

Table 2

Fatty acid (FA) composition (\%) of C. reticulates seed oil (RMO) in different SFE* fractions

\begin{tabular}{|c|c|c|c|c|c|}
\hline FA (1 $1^{\text {st }}$ fraction) & (\%) & $\mathrm{FA}\left(2^{\text {nd }}\right.$ fraction $)$ & $(\%)$ & FA ( $3^{\text {rd }}$ fraction $)$ & $(\%)$ \\
\hline Linoleic acid & $64.98 \pm 0.31$ & Linoleic acid & $66.02 \pm 0.74$ & Linoleic acid & $65.42 \pm 0.87$ \\
\hline Oleic acid & $16.13 \pm 0.85$ & Oleic acid & $16.45 \pm 0.29$ & Oleic acid & $16.56 \pm 0.12$ \\
\hline Palmitic acid & $8.13 \pm 0.53$ & Palmitic acid & $8.09 \pm 0.31$ & Palmitic acid & $8.33 \pm 0.42$ \\
\hline Stearic acid & $5.16 \pm 0.28$ & Stearic acid & $5.59 \pm 0.56$ & Stearic acid & $5.81 \pm 0.64$ \\
\hline Arachidic acid & $2.49 \pm 0.39$ & Arachidic acid & $2.92 \pm 0.82$ & - & - \\
\hline Linolelaidic acid & $0.55 \pm 0.18$ & Linolelaidic acid & $0.55 \pm 0.16$ & Linolelaidic acid & $0.56 \pm 0.36$ \\
\hline$\alpha$-linolenic acid & $0.21 \pm 0.62$ & $\alpha$-linolenic acid & $0.20 \pm 0.60$ & $\alpha$-linolenic acid & $3.32 \pm 0.22$ \\
\hline$\gamma$-linolenic acid & $0.18 \pm 0.40$ & $\gamma$-linolenic acid & $0.18 \pm 0.47$ & - & - \\
\hline Eicosanoic acid & $2.17 \pm 0.22$ & - & - & - & - \\
\hline$\Sigma S F A$ & 15.78 & & 16.60 & & 14.14 \\
\hline ¿MUFA & 18.30 & & 16.45 & & 16.56 \\
\hline ¿PUFA & 65.92 & & 66.95 & & 69.30 \\
\hline Ratio UFA/SFA & 5.3 & & 5.0 & & 6.0 \\
\hline
\end{tabular}

${ }^{*}$ All supercritical fluid extraction (SFE) fractions were performed at 600 bars and $40^{\circ} \mathrm{C}$. All determinations were carried out in triplicate and mean value $\pm S D$ reported. All determinations were carried out in triplicate and mean value $\pm S D$ reported. SFA, saturated fatty acids; MUFA, monounsaturated fatty acids; PUFA, polyunsaturated fatty acids; UFA, unsaturated fatty acids. 
acid (MUFA) and $65.92 \%$ of polyunsaturated fatty acid (PUFA). The $2^{\text {nd }}$ fraction obtained from SFE contained $16.60 \%$ SFA, $16.45 \%$ MUFA and $66.95 \%$ PUFA, whereas the $3^{\text {rd }}$ SFE fraction of $\mathrm{RMO}$ contained $14.14 \%$ SFA, $16.56 \%$ MUFA and $69.30 \%$ PUFA. It can also be noted that the percentage of PUFA was the highest in the three fractions. For $\mathrm{RMO}$, the highest SFA was from the $2^{\text {nd }}$ fraction, highest MUFA was from the $1^{\text {st }}$ fraction and highest PUFA came from the $3^{\text {rd }}$ SFE fraction. The number of different fatty acids obtained decreased with extraction time. For RMO $1^{\text {st }}$ fraction, there were 9 types of fatty acids in fraction 1 , in the $2^{\text {nd }}$ fraction there were 8 types and for the $3^{\text {rd }}$ fraction there were only 6 types of fatty acids present (Table 2 ). The ratios of unsaturated/saturated acid for RMO $1^{\text {st }}, 2^{\text {nd }}$ and $3^{\text {rd }}$ fractions are 5.3, 5.0 and 6.0 respectively, which is very high because of the low content of saturated fatty acids and high content of unsaturated fatty acid (Table 2).

This change of composition may be due to the differences in solubility of fatty acid in supercritical $\mathrm{CO}_{2}$ where soluble components can be extracted first.

The composition of the fatty acids by GC from the GLO is presented in Table 3. The major fatty acid present in the fractions from SFE for GLO was linoleic acid (64.7\%), followed by oleic acid (16.4\%), palmitic acid (9.1\%), stearic acid (5.2\%), arachidic acid (1.5\%). It can be observed that for GLO, the content of linoleic acid only decreased slightly from the $2^{\text {nd }}$ to the $3^{\text {rd }}$ fraction and no significant differences were found between the 1st and 2 nd fractions. There seems to be no significant differences in the contents of oleic, stearic and palmitic acids between the GLO fractions. This is not in accordance with the findings of $\mathrm{Yu}$ et al.
(1994) because a fatty acid with shorter chain length and higher degree of unsaturation has higher solubility. So, the percentage of linoleic acid should decrease with time whereas the percentage of oleic, stearic and palmitic should increase with time.

The fatty acid composition of GLO obtained from SFE $1^{\text {st }}$ fraction consisted of $16.35 \%$ SFA, $17.50 \%$ MUFA and $66.15 \%$ PUFA. The SFE $2^{\text {nd }}$ fraction consisted of $17.61 \%$ SFA, $16.59 \%$ MUFA and $65.80 \%$ PUFA, while the $3^{\text {rd }}$ SFE fraction of GLO contained $13.91 \%$ SFA, $15.57 \%$ MUFA and $70.52 \%$ PUFA. It can also be observed that the percentage of PUFA was highest in all fractions of SFE extraction for GLO. For GLO, the highest SFA was from the $2^{\text {nd }}$ fraction, the highest MUFA was from the $1^{\text {st }}$ fraction, and the highest PUFA was from the $3^{\text {rd }}$ fraction of Extraction. The ratio of saturated fatty acids to unsaturated fatty acids was 5.1, 4.7 and 6.2 for $1^{\text {st }}, 2^{\text {nd }}$, and $3^{\text {rd }}$ GLO fractions, respectively.

For GLO $1^{\text {st }}$ fraction, there were 16 types of fatty acids were present in fraction 1 , in the $2^{\text {nd }}$ fraction there were 8 types and for the $3^{\text {rd }}$ fraction there were only 6 types of fatty acids (Table 3). Linoleic acid was the predominant fatty acid in the oil from both melon seeds followed by oleic, palmitic and stearic acids with concentrations of $64,16,8.5$ and $6 \%$, respectively. These results were in good agreement with that of Norulaini et al., (2009) who studied the effects of supercritical carbon dioxide extraction parameters on virgin coconut oil and they reported that the composition of the fatty acid in the extracted oil varied, based on the extraction conditions. While Sanchez-Vicente et al., (2009) found no change in terms of fatty acid distribution in all the extracted peach seed oils at the conditions of

Table 3

Fatty acid composition (\%) of C. cantalupensis seed oil (GLO) in different SFE* fractions

\begin{tabular}{|c|c|c|c|c|c|}
\hline FA ( $1^{\text {st }}$ fraction) & $\%$ & FA ( $2^{\text {nd }}$ fraction $)$ & $\%$ & FA ( $3^{\text {rd }}$ fraction) & $\%$ \\
\hline Linoleic acid & $64.77 \pm 0.31$ & Linoleic acid & $64.67 \pm 0.61$ & Linoleic acid & $61.41 \pm 0.44$ \\
\hline Oleic acid & $16.42 \pm 0.25$ & Oleic acid & $16.59 \pm 0.15$ & Oleic acid & $15.57 \pm 0.69$ \\
\hline Palmitic acid & $9.19 \pm 0.64$ & Palmitic acid & $9.51 \pm 0.80$ & Palmitic acid & $8.67 \pm 0.72$ \\
\hline Stearic acid & $5.24 \pm 0.19$ & Stearic acid & $5.65 \pm 0.76$ & Stearic acid & $5.24 \pm 0.23$ \\
\hline Arachidic acid & $1.57 \pm 0.73$ & Arachidic acid & $2.45 \pm 0.28$ & - & - \\
\hline Linolelaidic acid & $0.70 \pm 0.26$ & Linolelaidic acid & $0.68 \pm 0.39$ & Linolelaidic acid & $0.63 \pm 0.54$ \\
\hline$\alpha$-Linolenic acid & $0.26 \pm 0.28$ & $\alpha$-Linolenic acid & $0.25 \pm 0.57$ & $\alpha$-linolenic acid & $8.49 \pm 0.10$ \\
\hline$\gamma$-Linolenic acid & $0.42 \pm 0.12$ & $\gamma$-Linolenic acid & $0.20 \pm 0.33$ & - & - \\
\hline Eicosanoic acid & $0.27 \pm 0.43$ & - & - & - & - \\
\hline Elaidic acid & $0.21 \pm 0.50$ & - & - & - & - \\
\hline Myristic acid & $0.19 \pm 0.81$ & & & - & - \\
\hline Palmitoleic acid_ & $0.18 \pm 0.33$ & - & - & - & - \\
\hline Pentadecyclic acid & $0.18 \pm 0.55$ & - & - & - & - \\
\hline Dimethyl-2-tridecenoic acid & $0.16 \pm 0.70$ & - & - & - & - \\
\hline Physeteric acid & $0.14 \pm 0.87$ & - & - & - & - \\
\hline 2-Heptadecylenic acid & $0.10 \pm 0.46$ & - & - & - & - \\
\hline$\Sigma$ SFA & 16.35 & & 17.61 & & 13.91 \\
\hline$\Sigma M U F A$ & 17.50 & & 16.59 & & 15.57 \\
\hline$\Sigma P U F A$ & 66.15 & & 65.80 & & 70.52 \\
\hline Ratio UFA/SFA & 5.1 & & 4.7 & & 6.2 \\
\hline
\end{tabular}

${ }^{*}$ All supercritical fluid extraction (SFE) fractions were performed at 600 bars and $40^{\circ} \mathrm{C}$. All determinations were carried out in triplicate and mean value $\pm S D$ reported. All determinations were carried out in triplicate and mean value $\pm S D$ reported. SFA, saturated fatty acids; MUFA, monounsaturated fatty acids; PUFA, polyunsaturated fatty acids; UFA, unsaturated fatty acids. 
supercritical extraction. The fatty acid profile of GLO and RMO resembled other Cucurbitaceae species, which were reported in previous studies (Mariod et al. 2008; Kamel et al. 1985; Badlfu 1991; Al-Khalifa 1996). Maria et al. (2001) reported linoleic acid, oleic, palmitic and stearic acids as predominant fatty acids in Cucumis melo Var. Saccharinus oil. Hemavatahy (1992) and Imbs and Pham (1995) also observed linoleic acid as the principal fatty acid followed by oleic acid from the oil extracted from an unspecified variety of musk melon.

\subsection{DPPH radical scavenging activity}

DPPH is a free radical compound and has been widely used to test the free radical-scavenging ability of various samples. It is a stable free radical with a characteristic absorption at $517 \mathrm{~nm}$ and was used to study the radical-scavenging effects of extracts. As antioxidants donate hydrogen radicals to this radical, the absorption decreases. The effect of GLO and RMO fractions $\left(1^{\text {st }}, 2^{\text {nd }}\right.$, and $\left.3 r d\right)$ on the reduction of DPPH radicals is shown in Figure 1. It was clear that the presence of antioxidants in the GLO and RMO fractions showed potent free radical scavenging activity on DPPH. Antioxidants, upon interaction with DPPH, either transfer an electron or a hydrogen atom to DPPH, thus neutralizing its free radical character (Naik et al. 2003). The color changes from purple to yellow and its absorbance at wavelength $517 \mathrm{~nm}$ decreases. The DPPH values for different GLO and RMO fractions against the control $(\mathrm{BHT})$ expressed as $\mathrm{IC}_{50}$ are shown in Fig. 1. Results are expressed in $I_{50}$ values $(\mu \mathrm{g} /$ $\mathrm{ml}$ ), and the $\mathrm{IC}_{50}$ values (concentration of sample required to scavenge $50 \%$ free radical or to prevent lipid peroxidation by $50 \%$ ) in GLO were found to be the least in the GLO $3^{\text {nd }}$ fraction $(6.5 \pm 0.25)$, followed by the GLO $2^{\text {nd }}$ fraction $(7.1 \pm 0.76)$, and the GLO $1^{\text {st }}$ fraction $(21.6 \pm 0.66)$. In the case of $\mathrm{RMO} I \mathrm{IC}_{50}$ values were found to be the least in the $3^{\text {nd }}$ fraction $(8.5 \pm 0.35)$, followed by the RMO $1^{\text {st }}$ fraction $(10.7 \pm 0.26)$, and the RMO $2^{\text {nd }}$ fraction $(21.3 \pm 0.46)$. The radical scavenging activities of the different fractions of RMO are in the order $3^{\text {rd }}$ better than $1^{\text {st }}$ and $t$ the $2^{\text {nd }}$ fraction gave the lowest antioxidant activity. In general, GLO showed significantly higher $(P<0.05)$ antioxidant activity than $\mathrm{RMO}$ except in the $1^{\text {st }}$ fraction where RMO showed higher antioxidant activity than GLO. The antioxidant activity of the different fractions from GLO and RMO may be attributed to components other than fatty acids in the oils. This activity may have been partly contributed by some constituents other than fatty acids e.g. tocopherols and phenolic compounds (Tasioula-Margari and Okogeri, 2001; Lee et al., 2002). For BHT, the DPPH tests showed that scavenging ability as $I_{50}$ was $0.29 \mu \mathrm{g} / \mathrm{ml}$. It can be observed that the synthetic antioxidant BHT is a stronger antioxidant in comparison to GLO and RMO seed oil extracts.

\subsection{Beta-carotene bleaching (BCB) antioxidant activity}

In the BCB assay, the oxidation of linoleic acid generates peroxyl free radicals due to the abstraction of a hydrogen atom from diallylic methylene groups of linoleic acid (Kumaran and Karunakaran, 2006). The free radical will then oxidize the highly unsaturated $\beta$-carotene. The presence of antioxidants in the fraction will minimize the oxidation of $\beta$-carotene by hydroperoxides. Hydroperoxides formed in this system will be neutralized by the antioxidants from the fractions. Thus, the degradation rate of $\beta$-carotene depends on the antioxidant activity of the fractions.

\section{$\square$ GLO $\square$ RMO $\square$ BHT}

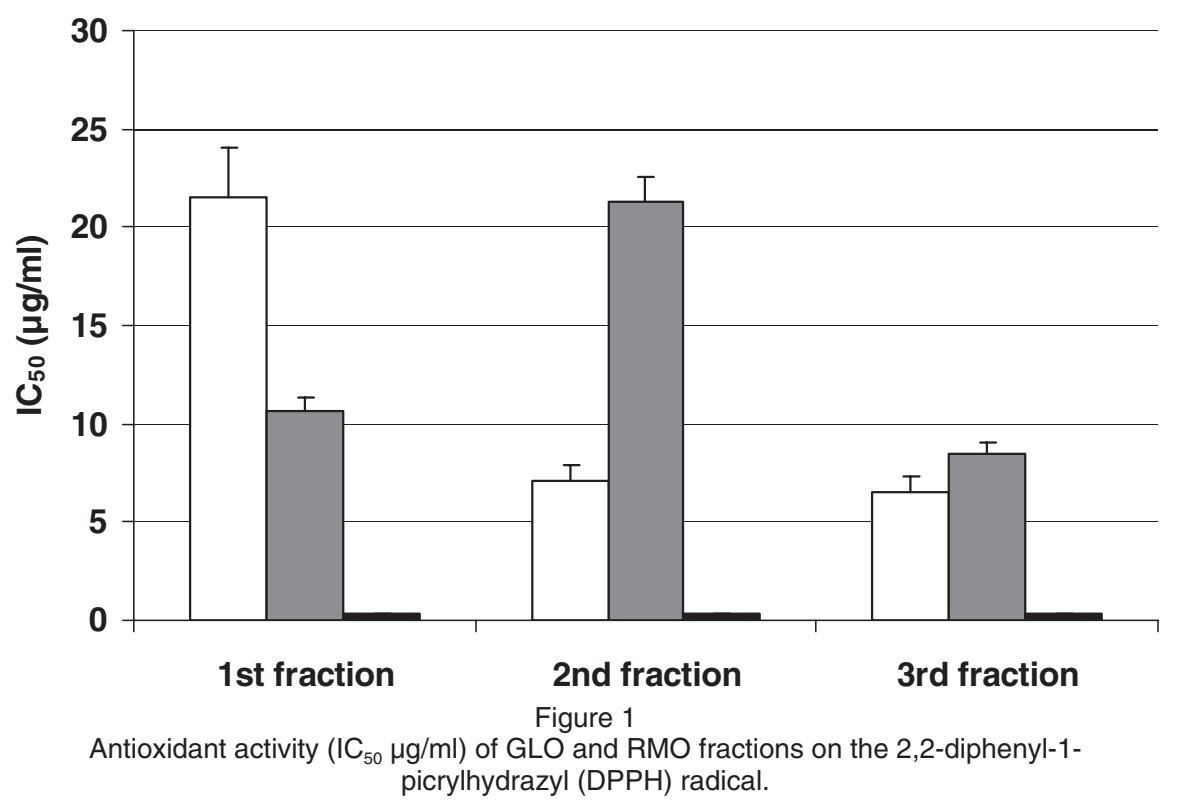


The antioxidant activity of the SFE fractions from GLO and RMO as measured by the $\beta$-carotene bleaching method are shown in Fig.2. The BCB mean activity of GLO $1^{\text {st }}$ fraction was 13.2 , for the $2^{\text {nd }}$ fraction was 55.6 and for the $3^{\text {rd }}$ fraction was 65.7. The BCB antioxidant test of GLO showed that the fractions were effective in the order: $3^{\text {rd }}>2^{\text {nd }}$ $>1^{\text {st }}$ (Fig. 2). The BCB mean activity of RMO for the $3^{\text {rd }}$ fraction was 78.4 , for the $2^{\text {nd }}$ fraction it was 51.0 and for the $1^{\text {st }}$ fraction it was 23.0. This means that the BCB antioxidant activity increased with time for both GLO and RMO. In the present study, RMO showed a higher ability to prevent the bleaching of $\beta$-carotene than that of GLO in the $1^{\text {st }}$ and $3^{\text {rd }}$ fractions and this antioxidant capacity can possibly be due to other oil components e.g. tocopherols, phytosterols and phenolic compounds, which were not investigated in this study. The BCB mean for BHT was 97.16 \pm 2.2 . It can be observed that the synthetic antioxidant, BHT has a stronger antioxidant activity when compared to GLO and $\mathrm{RMO}$ oil fractions.

For comparison of $D P P H$ and $B C B$ antioxidant activity methods GLO showed significantly higher $(P<0.05)$ antioxidant activity than RMO (except in the $1^{\text {st }}$ fraction) in the DPPH test while in contrast, RMO showed a higher ability to prevent the bleaching of $\beta$-carotene than that of GLO in the $1^{\text {st }}$ and $3^{\text {rd }}$ fractions and this is might be due to the different types of antioxidants that are assayed by the two methods.

\section{CONCLUSIONS}

Cantaloupe seed oils (RMO and GLO) serves as a new source of edible oil, the use of supercritical $\mathrm{CO}_{2}$ in cantaloupe oil extraction resulted in antioxidant- rich oil with different amounts and types of fatty acids. The number of fatty acids in the two oils decreased with increased extraction time. Based on the obtained results, RMO and GLO may play potential roles as health-promoting agents with high antioxidant activity in human diets, as well as providing valuable natural antioxidants for the pharmaceutical industry. Further studies are needed to evaluate other biological activities of RMO and GLO and to identify and characterize the active components which are responsible for antioxidant activity in these oils, other than fatty acids.

\section{REFERENCES}

Al-Khalifa AS. 1996. Physicochemical characteristics, fatty acid composition, and lipoxygenase activity of crude pumpkin and melon seed oils. Journal of Agricultrual Food Chemistry 44, 964-966.

Amarowicz R, Karamac M, Shahidi F. 2003. Antioxidant activity of phenolic fractions of lentil (Lens culinaris). Journal of Food Lipids 10, 1-10.

AOAC (1990). Official Methods of analysis, $14^{\text {th }}$ edition, Washington D.C. Association of Official Analytical Chemists.

AOCS (1993). Official Methods and Recommended Practices of the American Oil Chemists' Society, 4th edn., AOCS Press, Champaign, IL.

Badlfu GIO. 1991. Chemical and physical analyses of oils from four species of Cucurbitaceae. J. Am. Oil. Chem. Soc. 68, 428-432.

Baye T, Becker HC. 2004. Analyzing seed weight, fatty acid composition, oil, and protein contents in Vernonia galamensis germplasm by near-infrared reflectance spectroscopy. J. Am. Oil. Chem. Soc. 81, 641-645.

Bellakhdar J, Claisse R, Fleurentin J, Younus C. 1991. Repertory of standard herbal drugs in the Moroccan Pharmacopeia. Journal of Ethnopharmcology 35, 123-143.

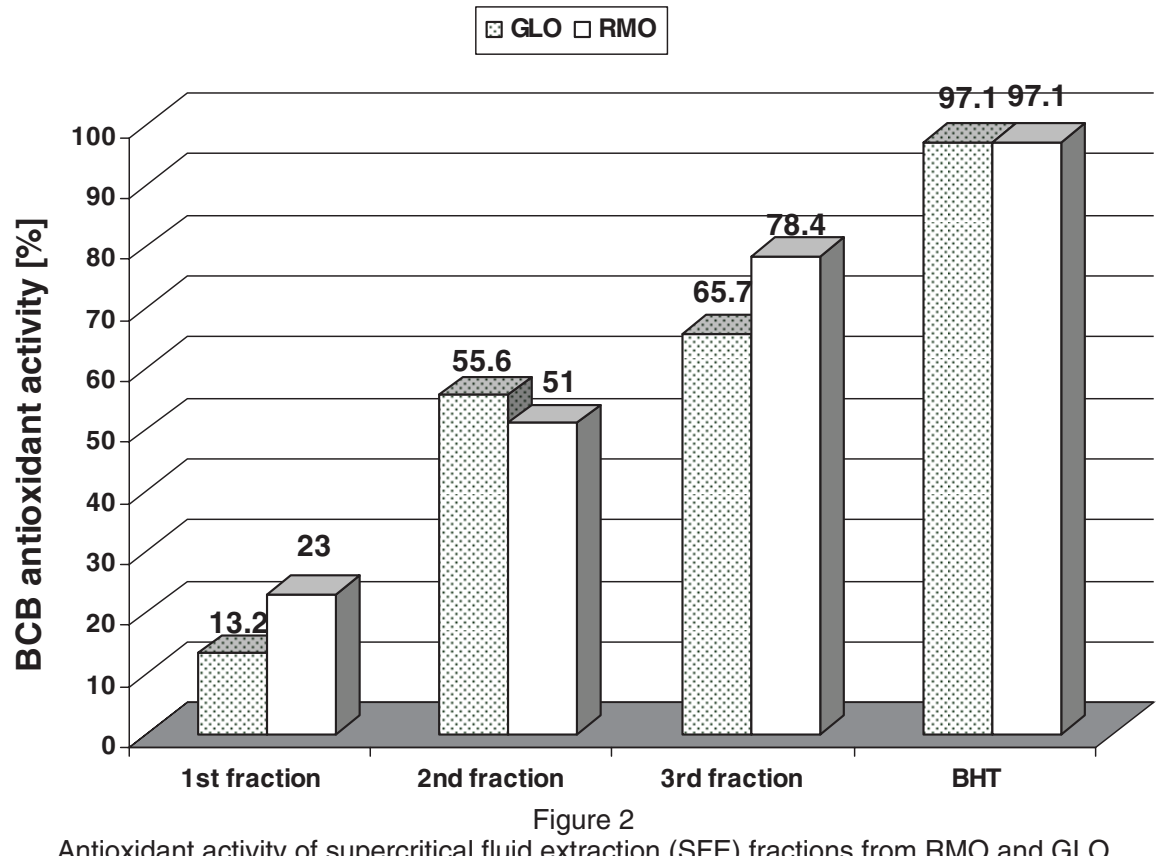

Antioxidant activity of supercritical fluid extraction (SFE) fractions from RMO and GLO in $\beta$-carotene-linoleate bleaching system (BCB). 
Bruhl L, and Matthaus B. 1999. Extraction of oilseeds by SFE - a comparison with other methods for the determination of the oil content. Journal of Analytical Chemistry 364, 631-634.

Budrat $P$, and Shotipruk A. 2009. Enhanced recovery of phenolic compounds from bitter melon (Momordica charantia) by subcritical water extraction. Separation and Purification Technology 66, 125-129

Chan KW, Ismail M. 2009. Supercritical carbon dioxide fluid extraction of Hibiscus cannabinus L. seed oil: A potential solvent-free and high antioxidative edible oil. Food Chemistry 114, 970-975

Dapkevicius A, Venskutonis R, Van Beek TA, Linssen $\mathrm{PH}$. 1998. Antioxidant activity of extracts obtained by different isolation procedures from some aromatic herbs grown in Lithuania. Journal of the Science of Food and Agriculture 77, 140-146.

El-Magoli SB, Morad MM, El-Fara AA. 1979. Evaluation of some Egyptian sweet melon seed oils. Fette Seifen Anstrichmittel 81, 201-203.

Frankel EN. 1996. Antioxidants in food and their impact on food quality. Food Chemistry 57, 51-55.

Friedrich JP, List GR. 1982. Characterization of soybean oil extracted by supercritical carbon dioxide and hexane. Journal of Agricultural and Food Chemistry, 30, 192-193.

Gerard D, May P. 2002. Herb and spice carbon dioxide extracts-versatile, safe ingredients for premium food and health food. Food Tech. 1-5.

Gomes PB, Mata VG, Rodrigues AE. 2007. Production of rose geranium oil using supercritical fluid extraction. The Journal of Supercritical Fluids 41, 50-60.

Gomez AM, Lopez CP, De la Ossa EM. 1996. Recovery of grape seed oil by liquid and supercritical carbon dioxide extraction: A comparison with conventional solvent extraction. The Chemical Engineering Journal and the Biochemical Engineering Journal 61, 227231.

Gordon MH. 1990. The mechanism of antioxidant action in vitro. In: B.J.F. Hudson, (Edit.), Food antioxidants, 1-18. Elsevier Science Publishers Ltd, England.

Hemavatahy, J. 1992. Lipid composition of melon (Cucumis melo) kernel. Journal of Food Composition and Analysis 5, 90-95.

Integrated Taxonomic System. www.itis.gov.retrived on 15 March 2007

Imbs AB, Pham LQ. 1995. Lipid composition of ten seed species from North Vietnam. J. Am. Oil. Chem. Soc. 72, 957-961

Kamal-Eldin A, Appelqvist LA. 1995. The effects of extraction methods on sesame oil stability. J. Am. Oil. Chem. Soc. 72, 967-969.

Kamel BS, Dawson H, Kakuda Y. 1985. Characteristics and composition of melon and grape seed oil and cakes. J. Am. Oil. Chem. Soc. 62, 881-883.

Kaur M, Mann SK, Hira CK, Bajaj S. 1988. Effect of musk melon (cucumis melo) seed supplementation on the nutritive value of wheat chapati. Journal of Food Science and Technology 25, 263-266.

King W. 2000. Advances in critical fluid technology for food processing. Food Science and Technology Today 14, 186-191.

Koleva II, van Beek TA, Linssen PH, de Groot A, Evstatieva LN. 2002. Screening of plant extracts for antioxidant activity: a comparative study on three testing methods. Phytochemical Analysis 13, 8-17.
Kumaran A, Karunakaran, R. 2006. Antioxidant and free radical scavenging activity of an aqueous extract of Coleus aromaticus. Food Chemistry 97, 109-114.

Lee JC, Kim HR, Kim J, Jang YS. 2002. Antioxidant property of an ethanol extract of the stem of Opuntia ficus-indica var Saboten. Journal of Agriculture and Food Chemistry 50, 6490-6496.

Leo L, Rescio L, Ciurlia L, Zacheo G. 2005. Supercritical carbon dioxide extraction of oil and $\alpha$-tocopherol from almond seeds. Journal of the Science of Food and Agriculture 85, 2167-2174.

Lu TJ, Gaspar F, Marriott R, Mellor S, Watkinson C, Al-Duri B. 2007. Extraction of borage seed oil by compressed $\mathrm{CO}_{2}$ : Effect of extraction parameters and modeling. The Journal of Supercritical Fluids 41, 6873.

Maria LS, de Mello Bora PS, Narain N. 2001. Fatty and Amino Acids Composition of Melon (Cucumis meloVar. saccharinus) Seeds. Journal of Food Composition and Analysis 14, 69-74.

Mariod A, Matthaus B. 2008. Fatty acids, tocopherols, sterols, phenolic profiles and oxidative stability of Cucumis melo Var. agrestis oil. Journal of Food Lipids 15, 56-67.

Norulaini NAN, Setianto WB, Zaidul ISM, Nawi AH, Azizi CYM, Mohd Omar AK. 2009. Effects of supercritical carbon dioxide extraction parameters on virgin coconut oil yield and medium-chain triglyceride content Food Chemistry 116, 193-197

Ou B, Huang D, Hampsch-Woodill M, Flanagan JA Deemer EK. 2002. Analysis of antioxidant activities of common vegetables employing oxygen radical absorbance capacity (ORAC) and ferric reducing antioxidant power (FRAP) assay: a comparative study. Journal of Agricultural and Food Chemistry 50, 3122-3128.

Rashwan MRA, El-Syiad SI, Seleim MA. 1993. Protein solubility, mineral content, amino acid composition and electrophoretic pattern of some gourd seeds. Acta Aliment. 22, 15-24.

Sanchez-Vicente Y, Cabanas A, Juan AR, Concepci PR. 2009. Supercritical fluid extraction of peach (Prunus persica) seed oil using carbon dioxide and ethanol Journal of Supercritical Fluids 49, 167-173.

Tasioula-Margari M, Okogeri O. 2001. Isolation and characterization of virgin olive oil phenolic compounds by HPLC/UV and GC-MS. Journal of Food Science 66, 530-534.

Tekin A, Velioglu S. 1993. A research of some compositional properties of melon seed and bitter almond. Gida 18, 365-367.

Teotia MS, Ramakrishna P. 1984. Chemistry and technology of melon seeds. Journal of Food Science and Technology 21, 332-337.

Xanthopoulou MN, Nomikos T, Fragopoulou F, Antonopoulou S. 2009. Antioxidant and lipoxygenase inhibitory activities of pumpkin seed extracts. Food Research International 42, 641-646

Yu ZR, Singh B, Rizvi SSH, Zollweg JA. 1994. Solubilities of fatty acids, fatty acid ester, triglycerides, and fats and oils in supercritical carbon dioxide. Journal of Supercritical Fluids 7, 51-59. 